\title{
Thought Experiments Naturalized ${ }^{\dagger}$
}

\section{[Düşünce Deneyleri Doğallaştırıldı]}

\author{
Nazım KEVEN *
}

Bilkent University

Received: 08.04.2021 / Accepted: 27.06.2021 DOI: $10.51404 /$ metazihin. 911684 Research Article

\begin{abstract}
Thought experiments have long been utilized in science and philosophy. They come in various forms, from Schrödinger's cat in physics to the Chinese room argument in philosophy. Although thought experiments are used widely, scant attention has been paid to how thought experiments actually work. In philosophy literature, it has been argued that thought experiments are a disguised form of meaning analysis. Thought experiments rely on the notion of analyticity on their basis, and therefore they should be abandoned. In this paper, I argue that if we distinguish conceivability type thought experiments commonly found in philosophy from factive thought experiments widely used in science, a viable methodological alternative can be found. I propose a set of criteria to define factive thought experiments precisely. I show how factive thought experiments can be successfully used in philosophical reasoning by giving examples, mainly from Wittgenstein's work. In this way, I argue, it is possible to naturalize thought experimentation.
\end{abstract}

Keywords: thought experiment, analyticity, conceivability, modality, Wittgenstein, language games.

Öz: Düşünce deneyleri uzun zamandır bilim ve felsefede kullanılıyor. Fizikte Schrödinger' in kedisinden felsefede Çince odası argümanına kadar birçok farklı yerde ve şekilde bulunabiliyorlar. Düşünce deneylerinin bu kadar sık kullanılmasına rağmen, düşünce deneylerinin nasıl çalıştığına çok az dikkat edilmiştir. Felsefe literatüründe, düşünce deneylerinin anlam analizinin kılık değiştirmiş formu olduğunu savunan görüşler mevcuttur. Bu görüşlere göre, düşünce deneyleri temelde analitik nosyonlara dayanmaktır ve bu yüzden terk edilmelidir. Bu makalede, eğer genelde felsefede bulunan kavranabilirliğe dayanan düşünce deneylerini genelde

\footnotetext{
+ Acknowledgment: This work was supported by the BAGEP Award of the Science Academy.

* Author Info: Assist. Prof.-Bilkent University, Facutly of Humanities and Letters, Department of Philosophy, Çankaya-Ankara,TÜRKIYE.

E-mail: nazımkeven@bilkent.edu.tr / Orcid Id: https://orcid.org/0000-0001-5368-8265
} 
bilimde kullanılan olgusal düşünce deneylerinden ayırırsak kullanışlı bir metodolojik alternatifin bulanabileceğini savunuyorum. Olgusal düşünce deneylerini daha net olarak tanımlamak için bir grup kriter sunuyorum. Olgusal düşünce deneylerinin felsefede nasıl kullanılabileceğini göstermek için özellikle Wittgenstein'ın çalışmalarından örnekler veriyorum. $\mathrm{Bu}$ şekilde, düşünce deneylerinin doğallaştırılabileceğini savunuyorum.

Anahtar Kelimeler: düşünce deneyi, analitiklik, kavranabilirlik, modalite, Wittgenstein, dil oyunları.

\section{Introduction}

Thought experiments have a long history in philosophy and science. The first thought experiments are found in the pre-Socratic philosophers. Throughout the medieval period, thought experimentation was almost the only method of science, and it continued to be used in philosophy and science in the early modern period. In the $20^{\text {th }}$ century, it acquired extensive popularity among analytic philosophers and scientists. What this picture suggests is that thought experiments are natural elements of human thinking. However, not enough attention has been directed towards the question "what governs what happens in a thought experiment?" (Horowitz \& Massey, 1991: 4) until recently. Consequently, especially after 1950, thought experiments had been widely employed in contemporary analytic philosophy without much attention paid to what is doing the actual job behind thought experiments.

Nowadays, fortunately, philosophers have begun to pay attention to thought experiments as a subject matter, and they have offered different answers to the question, "what is doing the heavy lifting in thought experiments?" Or to put it more precisely, "how can the contemplation of an imaginary scenario provide one with new true beliefs about contingent matters, and, assuming that it can do so, how are those new beliefs justified?" (Gendler, 2004: 1152) These kinds of worries have led to a general skepticism about thought experimentation. There are various kinds of concerns about thought experiments from relying on introspection to appeal to ordinary language ${ }^{1}$. In this paper, I will focus on one central problem that seems to underlie all of the other concerns and even, in a sense, encompasses all of the others in a nutshell. Gerald Massey, in Backdoor Analyticity (1991), argues that thought experiments are nothing but the reincarnation of analyticity. Therefore, all the problems that are related to analyticity are equally the problems of thought experiments. I contend that Massey's argument applies to one specific but, unfortunately, the most common type of thought experiment, i.e., conceivability arguments. However, I argue that there is another fruitful type, i.e., factive (or scientific) thought experiments, usually found in science, and the charge of analyticity does not apply to them. In this paper, I suggest that a large 
subset of factive thought experiments are available to philosophy and can be a viable methodological option in the future of philosophy.

\section{Thought Experiments as the Reincarnation of Analyticity}

According to Massey (1991), thought experiments are the last resort of philosophers' turf battle with scientists. The rise of modern science shrunk the cognitive space of philosophy, but philosophers were content with the good old a priori. However, the development of the non-Euclidian geometries cut off their access to a priori truths. To find another route to a priori truths, they developed meaning analysis. The notion of analyticity lies behind the meaning analysis. "The end products of meaning analysis had to be analytic truths, propositions true somehow or other by virtue of their meaning, however meaning itself was to be understood or explained" (Massey, 1991: 286). But the explanation of meaning turned out to be problematic, and Quine's "Two Dogmas of Empiricism" had the last word: The notion of analyticity has to be abandoned. Consequently, meaning analysis has to be abandoned as well since it presupposes analyticity. So philosophers tried to develop another method that does not presuppose analyticity, namely, thought experimentation. However, according to Massey, thought experimentation at the bottom also relies on analyticity.

Massey (1991) identifies thought experiments with conceivability arguments. He argues that conceivability and analyticity are virtually identical since there is a strong correlation between their governing laws and behaviors. He considers two correlations of the governing relations. The first one is the relationship of analyticity to logical truth (or falsehood), which is correlated with the corresponding relationship of conceivability (or inconceivability) to the logical possibility (or impossibility). Logical truth or falsehood is analytic by virtue of the constitutive laws of logic. The same laws of logic also regulate what is conceivable (or inconceivable). One's conceptions cannot violate the laws of logic. But what is conceivable is considered logically possible, whereas what is inconceivable is logically impossible. So, Massey (1991) argues, the role played by the laws of logic towards the analyticity of logical truth (or falsehood) is equivalent to the regulative role played by these rules in regard to conceivability (or inconceivability).

The second correlation that Massey (1991) considers is a priori access to necessity via analyticity, which is again correlated with a priori access to modality via conceivability. We have already mentioned that what is conceivable is considered logically possible, whereas what is inconceivable is deemed to be impossible. Conceivability (or inconceivability) is an a priori matter. Hence, both analyticity and conceivability warrant a priori access to necessity and possibility. Apart from these correlations, there is also an analogy between the responses that one might give to a conceivability argument and 
the responses that philosophers used to give to meaning analyses, especially in the case of counterexamples. In both cases, there is no strict way to confirm an argument and analysis. Success depends on the satisfaction of the parties. If satisfied with the counterexample, one could rest his case while the opponent abandons his theory. If not, one could simply ignore the counterexample. I agree with Massey that conceivability arguments are the reincarnation of analyticity. However, I disagree with his premise that thought experimentation is limited to conceivability arguments in philosophy. There is another type of thought experiment that does not work like conceivability arguments and does not rest on analyticity. It could be a viable option for philosophy.

\section{Analyticity-Free Thought Experiments}

Even though there is no consensus on the types of thought experiments in the literature, Tamar Gendler's (2002) tripartite taxonomy of thought experiments seems to cover the most common types. The first type, factive (or scientific) thought experiments, concerns what we think the facts of a situation would be. The second type, conceptual thought experiments, concerns what we consider the proper application of concepts. The third type is valuational; it involves the appropriate moral or aesthetic response to a situation (Gendler, 2000: 25). The first two types will be of much interest to our analyses, so let us examine them more closely.

Factive thought experiments are usually found in science. Galileo's refutation of the Aristotelian theory that heavier bodies fall faster than lighter ones is a paradigmatic illustration of a factive thought experiment. The thought experiment goes as follows:

Imagine that a heavy and a light body are strapped together and dropped from a significant height. What would the Aristotelian expect to be the natural speed of their combination? On the one hand, the lighter body should slow down the heavier one while the heavier body speeds up the lighter one, so their combination should fall with a speed that lies between the natural speeds of its components ... On the other hand, since the weight of the two bodies combined is greater than the weight of the heavy body alone, their combination should fall with a natural speed greater than that of the heavy body ... But then the combined body is predicted to fall both more quickly, and more slowly, than the heavy body alone. (Gendler, 2000: 41)

The inconsistency demonstrated by the thought experiment can be resolved only by giving up the theory that heavier bodies fall faster than lighter ones. Factive thought experiments resemble actual physical experiments both in their function and structure. Real experiments reveal relations between entities. In a similar vein, factive thought experiments show physical dependencies of the world. Actual experiments test a hypothesis or a theory in a physical setup, which is a detail of the world, and confirm or disconfirm it accordingly. Factive thought experiments test an ongoing scientific 
theory in a finer detail of the world and check whether it fits (Kuhn, 1964: 28). They succeed by showing an inconsistency within the conceptual framework of the theory. For instance, Aristotle's theory that heavier bodies fall faster than lighter ones appeals to our common sense knowledge of the world. After all, a stone falls faster than a feather. However, Galileo comes up with a situation that one would not easily encounter; nevertheless, it is an ordinary empirical situation. What Galileo depicts in his thought experiment is a detail of the world. Aristotle's theory should be capable of explaining that situation as successfully as it explains the more ordinary situations; otherwise, it should be given up. It is quite apparent that this is not the sort of thought experiment that Massey accuses of analyticity, and his arguments do not work against this type. Instead, he criticizes conceptual thought experiments.

Conceptual thought experiments are generally found in philosophy, and the most popular type is conceivability arguments. Frank Jackson's (1982) Mary, the scientist, thought experiment is a paradigmatic example. Imagine a scientist, Mary, who knows everything there is to know about the physics and the neurophysiology of colors, but who has never seen a colored object because she has lived in a white and black room with a black and white television screen for all her life. One day she is brought outside and given a colored screen. Jackson asks, do you think Mary learn anything new about colors? The anticipated answer is a big YES. Therefore, Jackson argues that since a person like Mary knows everything physical about color learns something new when she experiences color for the first time, it is inconceivable that phenomenal properties are identical to physical properties. Therefore, it is impossible to know what specific experiences are like based on the physical information or physical facts concerning these experiences.

Mary, the scientist, thought experiment concerns the proper application of the concept of 'knowledge.' It attempts to derive the impossibility of complete physical knowledge about human color vision from the inconceivability of knowing some facts about human color vision before the first-hand experience. However, there is no empirical way to assess this thought experiment. It is empirically possible to construct Mary the scientist experiment as depicted by Jackson, no matter how ethically suspect it would be. Even we could ask the person inside the room whether she learns something new, to which she probably would say yes. However, this is not enough to assess the thought experiment. We need to empirically evaluate whether knowing specific facts before the first-hand experience is inconceivable; otherwise, we cannot drive the impossibility in question. But there is no way to do that since it is a purely conceptual matter. According to physicalists, it is conceivable that physical information concerning specific experiences is sufficient to know what these experiences are like. In contrast, others think this is inconceivable, that no amount of physical information can suffice for what 
these experiences are like. So, the thought experiment relies on conceptual dependencies and attempts to access modality by a priori means. Thus, the assessment of the thought experiment depends on people's intuitions and their respective conceptual frameworks. Consequently, Jackson's Mary the scientist has become one of the most controversial thought experiments of the $20^{\text {th }}$ century. These considerations suggest that Massey's arguments apply with full force here, for at the bottom Mary the scientist thought experiment appears to rely heavily on analyticity.

Upon closer inspection, it seems that what distinguishes factive thought experiments from conceptual ones is their empirical verifiability. On the one hand, the more conceptual a thought experiment is, the more it relies on analyticity. On the other hand, the more factive a thought experiment is, the more empirical it becomes. Jackson's thought experiment represents one extreme and Galileo's another. The conceptual bit on the execution of a thought experiment should not be a problem. Both of the experiments are conceptual insofar as they are not empirically tested. The problem is conceptual thought experiment's reliance on conceivability (or inconceivability), which does not lend itself to empirical verification and depends heavily upon a particular conceptual framework. Factive thought experiments avoid dependence on solely conceivability by being empirically verifiable, i.e., either by being about how an entity would behave under a particular experimental setup or by making a verifiable prediction.

Moreover, factive thought experiments mimic the physical world in the world of thought. This way, they differentiate themselves from conceptual thought experiments. Consequently, while conceptual thought experiments that rely on conceivability (or inconceivability) can be fairly criticized for implicit analyticity, factive thought experiments cannot.

If factive thought experiments do not rely on analyticity, what governs what happens in a factive thought experiment? Fortunately, factive thought experiments can be justified in an evolutionary context. Events in the world of thought can indicate events in the physical world since there are pressures selecting minds that mimic patterns of nature (Sorensen, 1992: 63). There are selective pressures for the evolution of a cognitive ability to simulate events in the psychical world in our minds. Hence, the connection between the world of thought that simulates, and the simulated physical world is biological causation, not a mysterious bond. However, it would be naïve to suppose that our evolutionarily endowed modal intuitions are unlimited. If we look at the problems that our modal intuitions are evolved to solve, we can better understand. For example, the hunter-gatherers needed to track objects in space and time: to distinguish a friend from an enemy and recognize predator and prey, shelter, and foodstuffs. 
Moreover, they needed to manipulate objects and predict behavior. Thus, we can suppose that we have a stock of intuitions about space-time, biological and social relationships, belief-desire psychology, and causal reasoning. Humans also have excellent visual judgment and language mastery (Sorensen, 1992: 253). Furthermore, the performance of using these intuitions and abilities dramatically increases by experience. Hence, factive thought experiments that use these intuitions and skills depending on previously familiarized contexts are more than welcome.

The natural path to take to find thought experiments immune to the charge of analyticity is to assess the viability of factive thought experiments in philosophy. After all, factive thought experiments are not the private property of science. It is hard to employ bare factive thought experiments in philosophy. After all, the relation between two rocks is not much of an interest to a philosopher. There must be some element related to a philosophical conceptual framework in the kind of thought experiment we are looking for. Here we should carefully distinguish being associated with a conceptual framework from being dependent on it. As we have seen, conceivability arguments are dependent on a conceptual framework. If you change the framework, the results of the experiment will change as well. However, there is another well-known way for an experiment to be related to a conceptual framework without being dependent on it in philosophy, making use of science in any naturalized philosophy. Scientific thought experiments are also associated with a conceptual framework, i.e., a network of scientific theories, even though their results do not depend on those theories. Interpretation of the results is influenced by the theories nonetheless, which relates them to a conceptual framework. Thus, the solution to the problem of analyticity lingering within the domain of thought experiments is to strive for naturalization within this domain. That is to say; we need to naturalize thought experiments.

How can we naturalize thought experimentation? It must be clear by now how I think we can do that, namely by avoiding conceivability arguments and instead utilizing factive ones. We should use thought experiments that are factive (or scientific) in structure but philosophical in their functioning like any other actual scientific experiment used to support a philosophical position. Scientific thought experiments generally use modal intuitions that are fine-tuned by experience concerning space-time, causal reasoning, biological relations, and so on. As we have noted, these do not offer much interest to philosophy. However, philosophers can use modal intuitions finetuned by experience concerning social relations, belief-desire psychology, and language mastery. In what follows, first, I list some requirements such thought experiments ought to meet. Second, I argue that if a thought experiment meets these requirements, then it is immune to the charge of analyticity. Third, I give an actual example of such a 
thought experiment in philosophy to show that they already exist. Finally, I examine the consequences of this for philosophical methodology.

\section{Factive Thought Experiments in Philosophy}

The requirements that I propose for factive philosophical thought experiments are three in number. First, these thought experiments should be empirically verifiable. I accept the good old verification principle from logical positivists as it is. A thought experiment is empirically verifiable if we know what observations would lead us, under certain conditions, to accept the conclusion of the thought experiment as true, or reject it as false (Ayer, 1952: 36). Second, factive philosophical thought experiments should not be conceivability arguments. In other words, a thought experiment should not infer logical possibilities (or impossibilities) from our ability (or inability) to conceive such and such circumstances. However, we might still infer possibilities or impossibilities from the thought experiment itself in the same way we infer possibilities or impossibilities from facts about the world. Third, they must have some philosophical relevance as an actual scientific experiment could be used in philosophy, rather than hundreds of experiments out there that do not interest a philosopher.

Philosophical thought experiments that satisfy all three requirements do not rely on analyticity. The requirements do not need much defense against the charge of implicit analyticity. The first requirement guarantees a factive element in the thought experiment. It assures that the thought experiment would be factive in its structure. As we shall see in the example below, this criterion points to a critical distinction between the conclusion of the thought experiment and its philosophical import. The distinction is anticipated by our discussion of an experiment being related to a conceptual framework without depending on it. The conclusion of the thought experiment is empirical, either true or false, and not disputable. And that is the verifiable bit. The success of the thought experiment does not depend on the felt satisfaction of the parties. The philosophical import of the conclusion can be disputable, as is usual in philosophy. It is very similar to using the results of an actual scientific experiment in support of a philosophical thesis. In those cases, it is not the philosopher's job to discuss and evaluate the results of the experiment. Scientists can do that. The job of the philosopher is to examine the philosophical implications of that the result of that experiment. The second criterion makes thought experiments immune to Massey's criticisms as they are targeted to conceivability arguments. If the thought experiment does not rely on the $a$ priori conceivability-possibility (or inconceivability-impossibility) bridge, then the correlations that Massey questions don't apply to this type of thought experiment. The third criterion is meant to ensure that something philosophically significant remains in the thought experiment. 
To show that there are such thought experiments in philosophy, I give an example of the type of thought experiment outlined above, which does not rely on analyticity. My example comes from Wittgenstein's On Certainty (1972). Wittgenstein argues that in assessing the testimony of a witness, there are some principles of human inquiry, which govern when we ought to invoke a mistake and when we ought to accept the witness' testimony as it stands and try to contextualize it. The thought experiment goes as follows:

I fly from here to a part of the world where the people have only indefinite information, or none at all, about the possibility of flying. I tell them I have just flown there from.... They ask me if I might be mistaken... If I simply tell them that I can't be mistaken, that won't perhaps convince them; but it will if I describe the actual procedure to them. Then they will certainly not bring the possibility of a mistake into the question. But for all that even if they trust me - they might believe I had been dreaming or that magic had made me imagine it. (Wittgenstein, 1972: 671)

Does this thought experiment satisfy our requirements? First, it is verifiable. It is a matter of social psychology to verify the experiment's conclusion, i.e., that detailed explanation of the process or method of doing something helps to convince other people that the thing is doable or, at least, that the thing is sincerely asserted. We do not even need to verify it in its actual context, i.e., a person who flies to a community that doesn't know anything about flying. Instead, it would suffice to show using an experimental setup that people, who think that $X$ cannot be done, could be convinced of its possibility, or at least of our sincerity when we assert it, by explaining the method of doing X. It is observational rather than conceptual. Second, it does not derive possibilities from our ability to conceive a scenario or apply a concept. Instead, it extracts some information about human psychology from how we generally interact with each other in missing information cases. Third, it is considered to have philosophical significance since it raises interesting questions about invoking mistakes or taking seriously what at first sight seems improbable. Therefore, Wittgenstein's thought experiment meets our three requirements.

Here someone might object that being verifiable is not enough and thought experiments should be actually verified to avoid cases in which we have a verifiable thought experiment with false premises. The objector is right to point out that in some suspicious thought experiments, verification might actually be demanded before we can assess the philosophical import of the thought experiment. But this is a merit of the view rather than a limitation. Instead of getting lost in a hazy conceptual maze, verifiable thought experiments have an empirical option to fall back. However, this does not mean that every thought experiment needs to be verified. In most cases, 
verifiable thought experiments will not be iffy because they are factive like scientific thought experiments.

\section{Alternative Ways of Thought Experimentation in Philosophy}

I am aware that only a handful of thought experiments meet these requirements in the history of philosophy, and, probably, many of these would be Wittgenstein's. One could even argue that if a philosophical thought experiment meets these requirements, it cannot lead to knockdown philosophical results. If we look at our paradigmatic examples, while Jackson's Mary, the scientist, has occasioned a considerable debate about the possibility of non-physical properties, Wittgenstein's air traveler seems to be a minor philosophical detail. The requirements are so restrictive that the results you can accomplish within these boundaries are minimal and insignificant. First, I think it is possible to weaken the verification principle while still keeping the analyticity at bay. To find a weaker version of the verification principle, we need a detailed analysis of our hypothetical reasoning ability and parsing out in what circumstances it is reliable. It might turn out that a much weaker version of verifiability fits the bill. More and more factive thought experiments would be available to philosophy, and more exciting results could be welcomed.

Second, and more importantly, even though the results that a single thought experiment could accomplish are minimal, a series of factive thought experiments on a specific subject could lead to fruitful philosophical results. A single factive thought experiment might by itself be weak and not far-reaching, but a group of them could be even more potent than conceptual ones. Devising multiple factive thought experiments is precisely what Wittgenstein does in his later works and, I think, where the future of philosophy resides. Science uses a similar methodological approach. Even though there are some unique, groundbreaking experiments in the history of science, the general practice of science tends to favor a series of experiments in support of a scientific theory instead of a unique, unrepeatable groundbreaking experiment. The more experiments that one can provide for a scientific theory, the stronger the scientific theory. So, if the first step to naturalize thought experimentation is to use factive thought experiments, the second step is to use a series of thought experiments instead of a single one.

Wittgenstein has more to offer for thought experimentation. Language games can be considered a tool for thought experimentation in philosophy. Language games could become convenient to create a series of related thought experiments to clarify essential concepts of a philosophical issue. The term "language game" is one of those terms that can hardly be defined or explained but can only be shown. Not surprisingly, Wittgenstein does not offer a satisfying explanation or description but only gives 
examples of language games and remarks on them. Roughly speaking, we can say that a language game is a minuscule rule-governed social interaction. Here "minuscule" is used as a relative term and is meant to express the function of language games as building blocks of language analysis. Wittgenstein gives various examples of language games. To list some of them: ostensive definition, inventing a name for something (Wittgenstein, 1999: 13e), giving orders and obeying them, describing the appearance of an object, constructing an object from a description, reporting an event, speculating about an event, forming and testing a hypothesis, making up a story and reading it, play-acting, making a joke and telling it, solving a problem in practical arithmetic, translating from one language into another, asking, thanking, cursing, greeting, praying, etc. (Wittgenstein, 1999: 11-12e). The procedure to employ language games is to ask the reader to imagine a situation where two players act on something or learn something. For instance, take the language game of ostensive definition. Imagine a child learning names of things from his parents. So, in this language game, the child is brought up, or trained, to ask, "What is that called?" to which parents answer, "This is ....."

Do language games satisfy our three requirements? I will argue that they do. Language games fulfill the requirement of empirical verifiability. Language games are about actual uses of a language in a community. As factive thought experiments are concerned with the nature of objects out there in an imaginary experimental setup, language games are concerned with language uses out there in an imaginary arrangement. Anybody can go out and check the usage in question in a language game, as any scientist can check a factive thought experiment. When devising a factive thought experiment, a scientist relies on his grasp of physical phenomena and his mental simulation capacity of how objects would behave in such-and-such conditions from previously familiarized cases. Similarly, when a philosopher devises a language game in his native language, he relies on his grasp of the language and his mental simulation capacity of how a conversation would occur in his native language in suchand-such conditions from his previously accustomed cases.

Language games also satisfy the second requirement, i.e., they are not conceivability arguments. Instead, language games function more like existence proofs by means of examples. What they provide is that there exists such-and-such usage for such-andsuch word or sentence, or case. For instance, consider these series of language games:

If I say "an hour ago this table didn't exist" I probably mean that it was only made later on.

If I say "this mountain didn't exist then", I presumably mean that it was only formed later on-perhaps by a volcano. 
If I say "this mountain didn't exist half an hour ago", that is such a strange statement that it is not clear what I mean. Whether for example I mean something untrue but scientific. (...) Only the accustomed context allows what is meant to come through clearly. (Wittgenstein, 1972: 237)

It is quite apparent that these language games do not depend on the conceivability of the sentences or the situation. There is no reliance on inconceivability either; all of the sentences make sense, only in the third one it is hard to understand what is meant by the speaker even though the sentence makes perfect sense. Instead, these language games provide existence proof for the role of a familiar context to interpret statements. Here one tries to make sense of three structurally similar sentences. One can give potential interpretations to the first two according to previously accustomed contexts but fails to make any sense of the third since it does not fit any familiar context. Thus far, it is an empirical claim and does not depend on any particular conceptual framework. As they stand, these language games have significance for the philosophy of language, but Wittgenstein makes further use of them as an argument against the skepticism about earth's existence before one's birth. Here again, we have the difference between the conclusion of a thought experiment and its philosophical import. As long as we keep them separate and make the former empirical, we are on natural grounds.

In this paper, I argued that the philosopher's job in advancing thought experiments should be formulating verifiable experiments that are confirmable by a scientific discipline, i.e., to use naturalized thought experiments. Then, philosophers can investigate the philosophical implications of the experiment by foreseeing the result of it before any confirmation. However, this would inevitably slow down philosophers, as they would need to proceed with smaller and safer steps rather than giant unreliable and unverifiable leaps. I think this lower pace is preferable as long as we do not conceive achievement in philosophy as the construction of a single thought experiment by manipulating all the available parameters so that it seems to refute a prominent account in our minds. Instead, a series of closely connected factive thought experiments can provide philosophy a slower but more secure way to proceed.

\section{Bibliography}

Ayer, A. J. (1952). Language, Truth and Logic. New York: Dover.

Gendler, T. S. (2000). Thought Experiment: On the Powers and Limits of Imaginary Cases. NY: Garland Press.

Gendler, T. S. (2002). "Thought Experiment." In Encyclopedia of Cognitive Science. NY/London: Nature/Routledge. 
Gendler, T. S. (2004). "Thought Experiments Rethought-And Reperceived." Philosophy of Science, 71(5): 1152-1163. https://doi.org/10.1086/425239

Jackson, F. (1982). “Epiphenomenal Qualia.” Philosophical Quarterly, 32: 127-136.

Kuhn, T. (1964). "A Function for Thought Experiments." Reprinted in The Essential Tension: Selected Studies in Scientific Tradition and Change (1977) (pp. 240-265). University of Chicago Press.

Kuhn, T. (1977). The Essential Tension. Chicago: University of Chicago Press.

Massey, G. (1991). "Backdoor Analyticity." In Horowitz, T. and G. Massey (Eds.), Thought Experiments in Science and Philosophy (pp. 285-296). Savage, MD: Rowman and Littlefield.

Sorensen, R. (1992). Thought Experiments. New York: Oxford University Press.

Wittgenstein, L. (1999). Philosophical Investigations. Oxford: Blackwell.

Wittgenstein, L. (1972). On Certainty. New York: Harper Torch Books. 


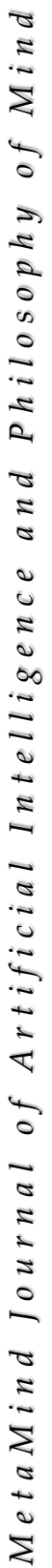

